\title{
Research on the Humanity Spirit in the "70s" Short Stories
}

\author{
Yongming Zhu \\ College of Chinese Language and Literature of Northwest Normal University, Gansu, Lanzhou, 730070
}

Keywords: "post-70s" writer; short stories; humanitarianism; survival and bioethics

\begin{abstract}
Strictly speaking, the "post-70s" writer was a literary writer born in the intergenerational period from 1970 to 1979. The "post-70s" writers are known as the current reading world for their short stories. Today, the reading circles have given more recognition and obsession to the "post-70s" writers, which is attributed to the "post-70s" writers' creations returning to the literary standard, that is, literature describes reality, reflects reality, and reflects its significance as a social ideology and value. The "post-70s" writers are known as the "problem novel" today. The most fundamental reason is that their novels present the living conditions of the bottom people in today's society, and give more humane and humanistic care, which is the most universal value of humanity.
\end{abstract}

\section{Introduction}

"Humanism" is a thought and theory about the nature, mission, status, value and personality development of human beings. It is the philosophical category of human development and change. Humanism as an era of thoughts and theories is in Formed after the fifteenth century, it was first expressed in literature and art, and later gradually penetrated into other fields. The term 'humanitarian' was derived from the Latin humanistas (the humane spirit), first in the Roman thinker MT Cicero, referring to An educational system that encourages individuals to achieve maximum development and a humane spirit. The emerging bourgeois thinkers of the 15th century believed that humanitarianism refers to the spirit of the Renaissance, that is, to learn and promote ancient Greek and Roman cultures. Only in the 19th century, humanitarianism has always been an important ideological weapon for the bourgeoisie to establish and consolidate the class system."1 From the interpretation of the encyclopedia, the era of "humanism" was born in the Western feudal bourgeois era. With the development of the times and changes in social systems, scholars have a new interpretation of humanism: "In a nutshell, humanitarianism is based on humanity, with individualism and fraternity as the core, with 'freedom' and 'equality. ', 'Bo'ai' is the three major slogans, advocating a rational doctrine of reason." 2 Anhui University professor Wang Damin believes: "Humanitarianism is a kind of humanity and humanity, with good and love as the core, people-oriented, and people The survival, rights, dignity, value, the highest goal of human freedom, happiness and development, and the ethical thoughts or thoughts of humanity and universal concepts (such as freedom, equality, fraternity, peace, tolerance, sympathy, etc.) When it evolves into a trend, it forms, thoughts or movements.” 3 In fact, Chinese modern writers such as Lu Xun and Yu Dafu have long been involved in humanitarian propositions.

The rise of China's contemporary "humanitarian" literary trend is the rise of the policy of "a hundred flowers bloom and a hundred schools of thought contend" after the founding of New China. After the end of the "Cultural Revolution", in addition to painstaking efforts, some artists and theorists such as He Qifang began to profoundly reflect and explore the issues of humanity and humanitarianism and the 'alienation'. After the 1980s, the literary trend of humanitarianism and human nature was constantly ignited in the Chinese literary world. After the Chinese society entered globalization in the 1990s, the tide of the market economy began to rise, and the negative factors such as money worship, forgiveness, ideals, and moral disintegration were once rampant. Then the "humanistic spirit" crisis was put forward and heated debates. At this time, the appeal of the humanitarian spirit is also stronger.

The writing of the "post-70s" on the human spirit stems from their growing environment and background. The characteristics of globalization, the Internet, and the changing social 
transformation have imperceptibly influenced the growth and values of this generation. In their creations, they use short stories as a window to look at the real society, and strive to see a generation of people who have been "posted" during the period of social transformation. The short stories of Ge Liang, Ma Xiaoquan, Huang Lan, Mara, Zhang Xuedong, Dai Lai and Huang Yongmei from this group of writers show a strong humanitarian spirit.

\section{The Humane Care in the Bottom of the Living Circle}

The "post-70s" writers are based on the literary soil of realism, and use the special style of short stories to describe their true colors and strive to find a place for literature. At the same time, they inherited the fine tradition of realistic meaning, and with a keen eye, they worked hard to care for the abandoned generation in the low-level society. Therefore, many novels show extremely strong humane care. In the writing of the humane spirit, the academic circles have recognized the value of the short stories of the "post-70s" writers. The humanistic thoughts reflect the creative position and basic concepts of the "post-70s". In this respect, they adhere to the "people-oriented" creative concept, and strive to capture the cross-section of society, highlighting the living conditions of the forgotten generation of the elderly.

Yang's short story "The Gossip of the Weekend" takes the family as a narrative point of view and starts this topic. The novel portrays a father who was abandoned by his son in the country. He spends his lonely and lonely years with his cat all day long. After the normal exchanges with young Yan Yan were also passed down into the scandal, the old man had to bring the cat to the son of the county seat. Some anecdotes also followed, so the daughter Chunlan returned to the mother to marry, and the son acknowledged this fact. He complained and scolded his father. When Xiaoyan's husband led a helper to claim a 20,000 yuan mental loss, the old man admitted that their interaction was innocent. The son readily agreed to 5 yuan, the old man could not accept this fact and left home. The novel begins with two path narratives. The son of Zhang Jin's wife Chunlan's mother was also alone. After Chunlan returned home, she heard the mother's rumor that she was very unhappy. After the old chapter left, Chunlan was called home by her husband to find the old chapter. In the green flower belt of an overpass, they found an old chapter that they did not want to go home. In the process of persuading the old chapter, Chunlan received an accidental phone call saying that her mother fell into the ditch and sprained her foot. When she was helpless, the man surnamed Liu appeared on the phone. She wanted to take care of her mother but she couldn't reach it. She had to pay the man named Liu to take care of her mother. In a friendly "Liu Shu", she understood the old man's difficulty. Ge Liang, Zhang Chu, Yang Xie, Mara, Fu Xiuying and other "post-70s" writers have strong human sentiments in their short stories. Most of this sentiment is reflected in the understanding and care of the older generation. Ge Liang's "William" profoundly wrote the grandfather's state of the next year. Fu Xiuying's "Old House" gave birth to nine daughters, but it still made the master dissatisfied. In Mara's short story "The Boy on the Balcony", a retired lonely old man was written with a sentimental sentiment. After the old man moved into the community, the lonely time began to accompany him. In addition to watching TV, cooking, reading newspapers and lonely, he spent three months. One day the neighbor finally came, and he also took a child, so the old man In life, there is sunshine. Every day, the elderly communicate with children through the balcony. Gradually, the relationship between the old and the young has a blood relationship like "grandchildren". Later, the children's parents suddenly put the child was locked up and the association with the old man was stopped. The lonely old man was finally admitted to the hospital. The short story was written in the manuscript: "The novel has all the elements of 'chicken soup', but it has sent a different kind of profoundness. From the novel, the text can interpret many meanings, the loneliness of the elderly living alone, the children of the city. Loneliness, the seemingly politeness between neighbors, and even the relationship between prevention..."4

In our time, material life is rich, and spiritual life is extremely lacking. Especially since the generation of the fathers, it has been placed on the edge of the family and become the surplus of the family. This is triggered by the social status quo of the transformation of the countryside, the migration of people, and the adjustment of the social structure in the modernization process in 
China since modern times. This kind of writing shows the "post-70s" writer's fear and warmth of history, sighing and sighing on himself. In the face of such a situation, they vaguely expressed the survival of deduction, gratitude, presentation, and initiative. This is far from the confession of the "post-80s" on the "losers" and the historical memory.

\section{Family Survival Ethics and Humane Care}

In terms of the growth environment, the "post-70s" writers are the generations that grew up in the cracks. Unlike the "post-80s", they all grew up in the great era of reform and opening up, and because they are mostly only children, they are favored by their parents, so they are unrestrained. It is not like "post-60s", it has continued to have more traditions and has a deeper traditional cultural heritage. The "post-70s" sandwiched in the middle became a generation that was not high, low, not painful, unloving, and neglected. They grew up in a family environment similar to the "Grand View Garden” of sisters, and they were far from being "protected”. Therefore, they were not selfish and shared with others.

China is an ethical country based on blood and a family-based ethic. "Blood is the origin and starting point of ethics, and its expression is the application of blood relatives." 5 Since the new era, with the implementation and promotion of the family planning policy, the family members with blood as the link have been shrinking, and the scope of the family has once again restricted, the elders under the ethical ethics claim that for the "post-80s" and "post-90s" people, many have become synonymous with vulgarity. Therefore, the exchanges between many elders, uncles and juniors have broken. The crane driver writer Ghost Gold's "Rainbow" (fiction selection, 2016, issue 2 ) is a short story that is full of "cold tones". The whole article uses humanitarianism to connect with the ruthless blood relationship in the family. At the beginning of the novel, I confessed to a family who accidentally lost her parents. Rainbow is the boss of her sister. After her parents died, when the family was tortured by the father's scene and hunger all day long, the uncle's accident came. It is to push this run-down home to a desperate situation. The ruthless second uncle asked for the sister's house, and the three sisters had no choice but to live in the dilapidated bomb shelter and live a harder day. The rainbow image of her sister, who is only fifteen years old, is in tears. The price she pays for the survival of the family makes people feel the symbiosis of the great sacrifice spirit and the humble existence. The appeal of the novel stems from the enormous emotional power and tragic power of love and sacrifice presented in the tragic fate, rather than the tragic life itself. The novel makes a strong double-line comparison between the two generations of the concept of family affair, highlighting the "excellent feeling" in the generation of the father, and flashing "deep love" in the generation of the generation. Two generations have formed two distinct emotional contrasts, and this contrast is also a strong confrontation between the characters and the real world. At the end of the novel, the rainbow was completely smothered by the security guard Li Liande in order to save his younger brother. The compromise of the rainbow is the spiritual independence of the characters, implying the compromise of the "post-70s" writers to the market economy and the media era. This short piece is completely developed in a cool tone, and the narrative tone is similar to Xiao Hong's "Hulan River Biography".

The home is an environment in which people grow up. The "post-70s" writers re-examine the distortion and complexity of human nature in the social fission era. In the 1930s and 1940s, Ba Jin created the novel "Home". In the new century, some writers of the "70s" refocused their attention on the unique space of "home" and rewritten their homes. Reflection, this kind of reflection is a rethinking of human nature. "After the 70s" is not growing in the "greenhouse", but in the "poor home." They are the generation that knows the most about family relationships. Their short stories are often written in a large family field, which constitutes multiple relationships of characters. From the perspective of children, Li Yunlei's "The Thief and Flowers" profoundly wrote the spiritual destruction caused by the divorce of parents to a childlike heart. Not all short writings are full of cool colors. Relatively speaking, some family ethics writing is inevitably accompanied by "light" and "warm." Chen Xiaolan's "Desert Bodhi" is a warm-toned family ethic narrative. The novel is similar to the scar theme. In order to keep the child, the story of the maiden was a nun at the age of 
19, and was rushed home during the Cultural Revolution to become a target of criticism. The strategist wanted to starve her to death. In order to survive, she had to flee to a different place and give it to others. Dry and rough, barely strive for a life-sustaining meal. The goddess who experienced spiritual damage knows the world and cares for her three scorpions. When the times change, they regain the tree garden and help the three children to study. In the most difficult time, the maiden sells. The maiden became the enlightenment teacher of the three children, and became the light in their lives. She gave the children kindness, piety and love. The goddess in the novel is both a victim of an era and an awakening person in an era. She recognizes the philosophy of life in the new era of "everything borrows, only has a high reading". The maiden is a symbol of human goodness and a manifestation of perfect personality. Her body reflects the most valuable aspect of the human spirit.

\section{Life Ethics and Humane Care}

Since the new period, anthropological ontology, life ontology and subjective spiritual ontology have also risen to the hot topic of academic discussion. Through discussion, the philosophy of life advocated by Nietzsche, Schopenhauer, Dilthey, Simmel, Bergson and others was introduced into the field of literary studies. Some commentators believe that life constitutes the ontology of art, that is, "from the subject to the skill, from the style to the genre, from the form to the content, all of which express the life as the ontology." 16 The initiative of these creation theories caused the "post-70s" writers to Literature expresses the care of life and the pursuit of "authentic purity."

In the recent works of "70s", the care of life has touched the hearts of many readers. In Ge Liang's novel "Beibei", Zum Zhaode is the wife of the warlord Shi Yuxi. After the family is broken, the money is gone, and the people go to the building. She faces the coercion and provocation of the bandits to protect the sister family. The choice of life and the bandits are the same. The wonderful novel of the novel is a supplement to her. It is she who gave the "Redwood Scorpion" to the church to help the church redeem the lives of 11 children from the Japanese. In the "Elephant" of Zhang Chu, Sun Zhigang and his wife searched for the benefactors who helped the sick child Sun Mingjing. The patient Cheng Gang just helped Sun Mingjing to find his biological parents, and there was no lack of expression of warmth in life. Jiang Lin's "The Night of the Gods" is based on a story of a car accident that was raised six years ago. The storytellers have had a spiritual dialogue with nine passers-by from the public.

"All things are light, above life" is the life consciousness expressed in the "post-70s" novel. The writing of life after "70s" has undoubtedly become a beautiful scene in the novel. They use life as a borderless topic, using fictional and non-fictional elements to unfold narratives around life. Zhu Shanpo's "Bone Bone Soup" unfolds the story in the boundary between life and death, extending the thinking boundary of life to the topic of life. Chai Chunya's "The Silent Mani Song" borrows the life philosophy of "reincarnation" in Tibetan Buddhism. In the field where the urban and western life are interlaced, the mysterious narrative of the reincarnation of the wanderer's soul is unfolded, which proves the life of the bottom. Lu Shunmin's non-fictional long story "The Farmer of the World" gave a deep rational reflection on the death of 38 dead people, and gave angry accusations to the fake media. In the "Little Life" of Sheng Ke, I will describe the unexpected pregnancy of the 18-year-old sister of the protagonist, whether to marry the "little boy" who is in trouble, how to marry, whether to give birth to the child and other difficult problems. In the dispute, my sister made two decisions: First, refused to marry the kid; second, she was determined to give birth to the child. The sister's decision highlights the awakening of motherhood and highlights the sense of respect and compassion for life. After the defeat of the protagonist "I" in the "Suiyuan" of Yan Zhou, the two-line narrative of Yunyou and returning home deeply reproduces the void and emptiness of life. Mara's short "The Rat" reflects the human desire for new life and appeals from an ethical perspective. The bleak scene of the separation of flesh and blood between the mother and the child in the novel is quite as ridiculous as the "Mother of the Slave".

In short, the "post-70s" writers inherited the fine traditions of scar literature, reflective literature, reform literature, and educated youth literature, and innovated. They missed the first literary 
literature, not a disjunction of creative ideas, but a kind of detachment. Their short stories have a strong story, unlike the fragmented narratives like Ma Yuan and Zhaxi Dawa. A novel has become a whole, and it is very impressive after reading.

\section{References}

[1]"China Encyclopedia. Philosophy", Beijing: China Encyclopedia Publishing House, 1987 edition, p. 696.

[2] Du Weiguo: "Research on the Trend of Thought of Modern Humanitarian Literature in China", Hunan: Yuelu Shushe 2007 edition, p. 8.

[3] Wang Damin: "The History of Contemporary Chinese Humanitarian Literature Trends", Shanghai: Shanghai People's Publishing House, 2013 edition, p. 10, p. 239

[4] "The Selection of Novels", No. 2, 2016, p. 62. 